University of New Hampshire

University of New Hampshire Scholars' Repository

$11-8-2019$

\title{
Public Impact-Focused Research Survey Results
}

\author{
Kevin H. Gardner \\ University of New Hampshire, Durham, kevin.gardner@unh.edu \\ Scott Slovic \\ University of Idaho, slovic@uidaho.edu \\ Terri Goss-Kinzy \\ Western Michigan University, terri.kinzy@wmich.edu \\ Christopher Keane \\ Washington State University, chris.keane@wsu.edu
}

Follow this and additional works at: https://scholars.unh.edu/research_scholarship

\section{Recommended Citation}

Gardner, K.H., S. Slovic, T. Goss-Kinzy, and C. Keane (2019). Public Impact-Focused Research Survey

Results. UNH Scholars' Repository https://dx.doi.org/10.34051/p/2019.3

This Report is brought to you for free and open access by the Research Institutes, Centers and Programs at University of New Hampshire Scholars' Repository. It has been accepted for inclusion in Office of Research Scholarship by an authorized administrator of University of New Hampshire Scholars' Repository. For more information, please contact Scholarly.Communication@unh.edu. 


\section{Public Impact-Focused Research Survey Results}

November 8, 2019

Kevin H. Gardner, University of New Hampshire (corresponding author).

Scott Slovic, University of Idaho

Terri Goss-Kinzy, Western Michigan University

Chris Keane, University of Washington

Introduction

The Association of Public and Land Grant Universities (APLU) Council on Research (COR) led an initiative to define, identify, and develop a recommended path forward for public impact research (PIR). A survey was conducted of APLU institution in order to:

1. To characterize the extent of public impact research (PIR) occurring at APLU institutions.

2. To understand how institutions (or leaders within institutions) think about, define, and communicate about this type of work.

3. To provide perspectives about the challenges, opportunities, and rewards that may be associated with this type of scholarship.

Responses were received from a diverse set of seventy public and land grant universities (APLU total membership was 239 universities at the time of this survey). Research expenditures at responding institutions ranged from $\$ 5$ million to over $\$ 1$ billion in FY 2017, and respondents included Hispanicserving institutions, historically black universities, IEP-designated universities, and were received from 26 US states and one Canadian province.

This document contains the complete set of de-identified responses to the survey. The intent is to make this broadly available and accessible to individuals or groups who may want to further analyze or use these results. Recommended citation is:

Q1 - Thank you for taking the time to answer this brief survey about Public Impact-Focused Research, which will provide useful data for the APLU to understand the experiences universities have had in carrying out this type of research. Results from this survey will not be attributable to any individuals nor institutions and none of the survey questions require responses.

The APLU Public Impact-Focused Research Initiative has four goals:

1. Develop strategies for enhancing the public impact of each University's research portfolio. 
2. Reduce barriers to Public Impact-Focused Research in public and land grant universities and their research partners.

3. Develop language to describe and showcase impacts from Public Impact-Focused Research.

4. Ensure that this initiative also strengthens support for fundamental research.

Working definition: Public Impact-Focused Research is research that is conducted for the explicit purpose of benefiting the public.

How clear is this working definition of Public Impact-Focused Research?

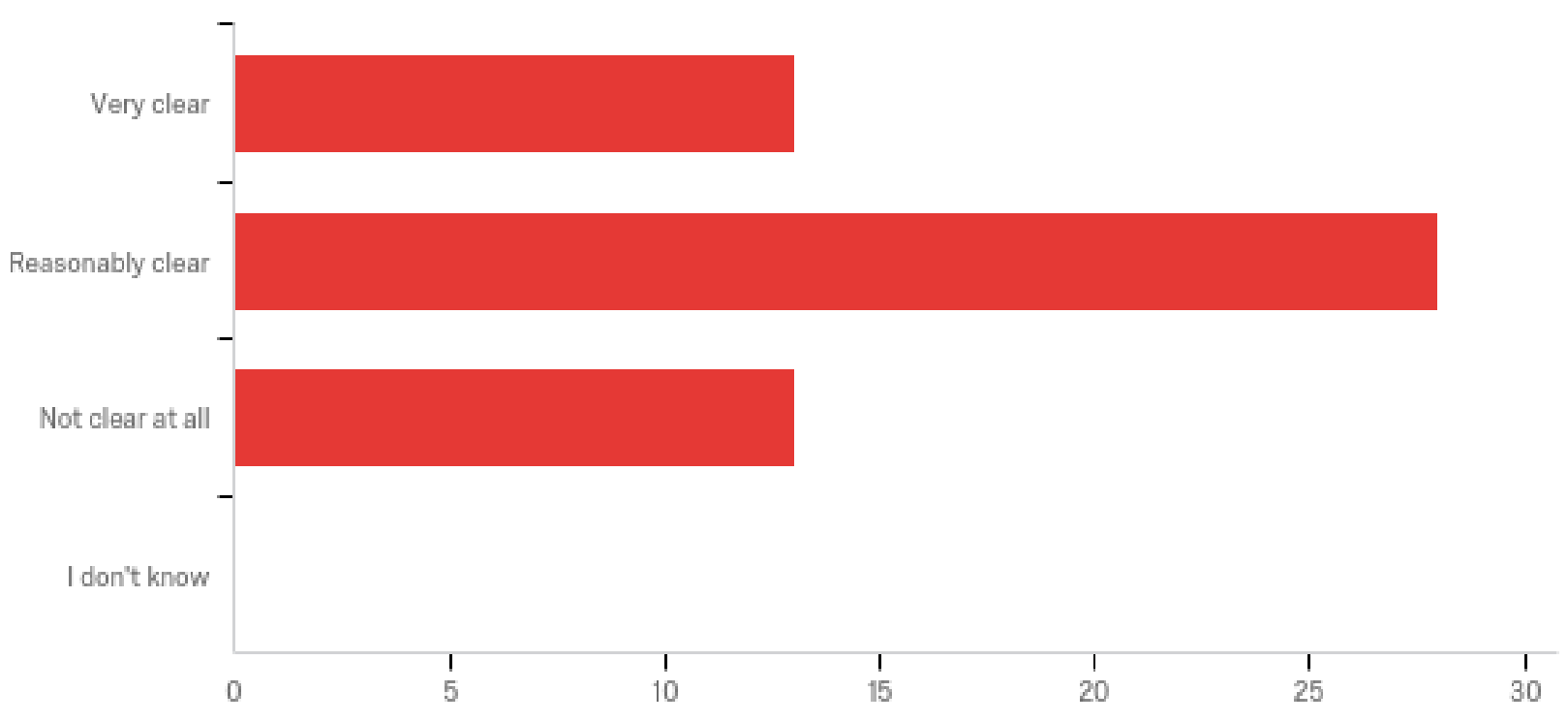

Q2 - For a research initiative to merit the "Public Impact-focused Research" label, in addition to explicitly benefiting the public I believe the research must... (select all that apply) 


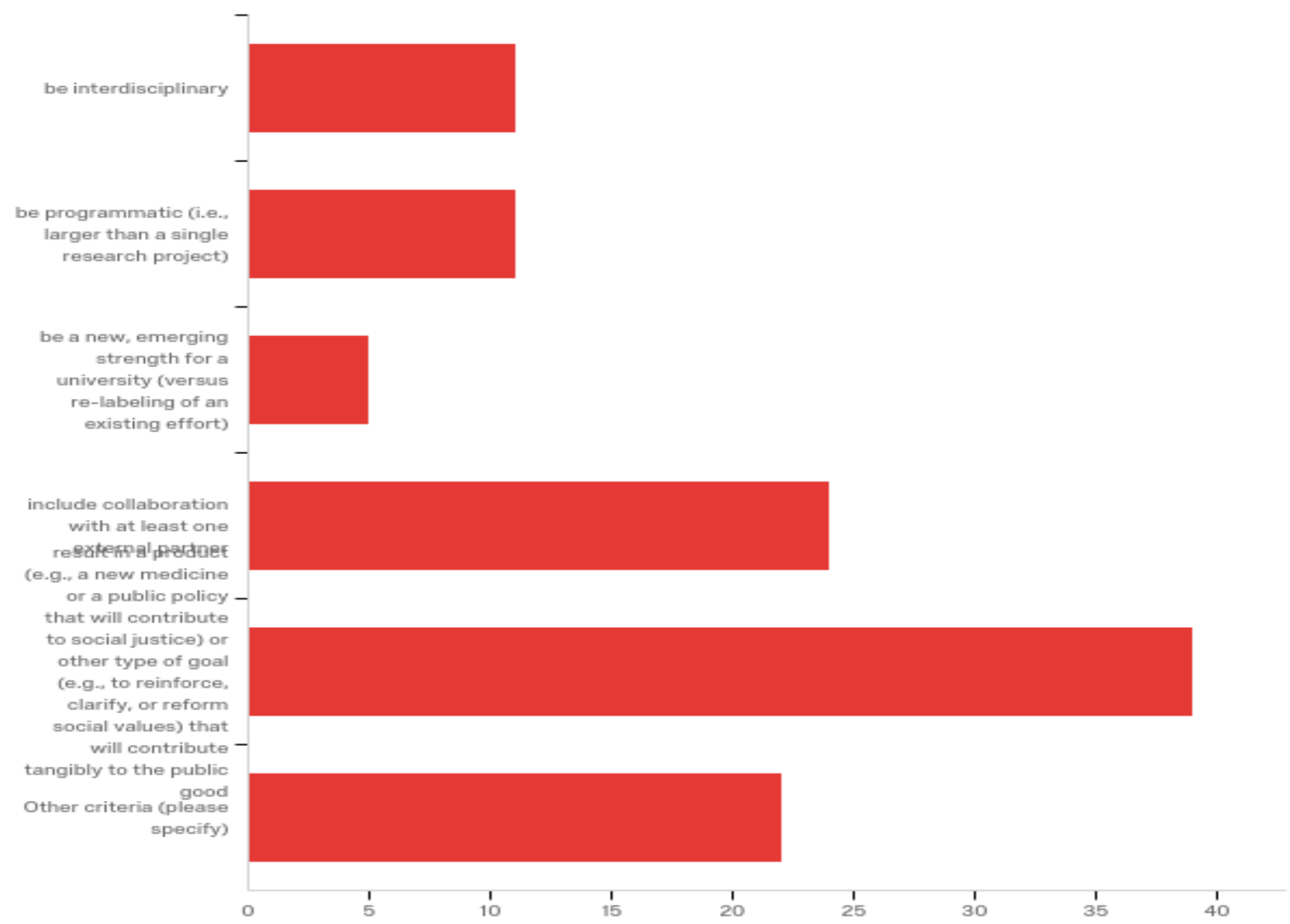

\section{Q2 Other criteria (please specify) - TEXT RESPONSES}

I would modify the 5th description to say "directed toward resulting in a product..." since you cannot determine the actual outcomes of research projects

research that is influential and persuasive in changing minds and behaviors but may not be tangible.

It doesn't need to be any of these things

I don't believe other criteria are needed beyond explicitly focused on public impact, where public impact should be easily understood by many people as something tangible and specific they can appreciate

Must engage community partners as co-investigators and co-producer of the research

I think that the definition needs to be more specific than what is written in Q1 but I'm not necessarily sure what it should be. I think what needs to be front and center is a tangible public impact/change/intervention/goal that is public impact focused so that general discovery doesn't fit unless that discovery was taken to have an immediate (without further research) impact on the community. I think we need to work on the definition again as a group.

Could be all of the above, including a single discipline, single PI project. Let's not limit this.

For research "that is conducted for the explicit purpose of benefiting the public", it could, but does not need to have any of these characteristics. It is somewhat disingenuous to say projects that have these characteristics are in the public good.

it must include a process for continuing engagement with community partners and stakeholders

relevant to the target issue, population and respectful of cultural and regional mores. 
I believe it could be any one of these but doesn't have to be any specific one.

Must include leading-edge research that develops new knowledge

Must include lead-edge research and generate new knowledge

In above response (result in a product), I do not mean to imply that the product would be at final stage when the research is completed, but rather provide the basis for the next actions that would be taken to bring the discovery/outcome to the public. If that was not your meaning, then please uncheck my response to that option. Recommend revising must to "most likely includes". Public impact-focused research is not university-focused, instead it is a culture, a contribution that underlies the disciplinary expertise.

recommend revising must to "more likely than not" and if this is Public - Impact focused why is it being anchored in the University?

involve input from the public on what their true problems are that research could solve rather than making the assumption that we know

Be collaborative with Cooperative Extension efforts (an internal effort for LGUs)

Clearly identifies how the research has a public impact

None of the above

The top 4 criteria above are desirable but should not be required to merit the label.

I think the points above should not be a criteria. They are all too narrowing. Bottom line is if the work is intended to be impactful to the public -- then guess what --it is Public Impact Focused.

\section{Q3 - In learning about the concept or being encouraged to engage in Public Impact-Focused Research, researchers at my institution are most likely to:}

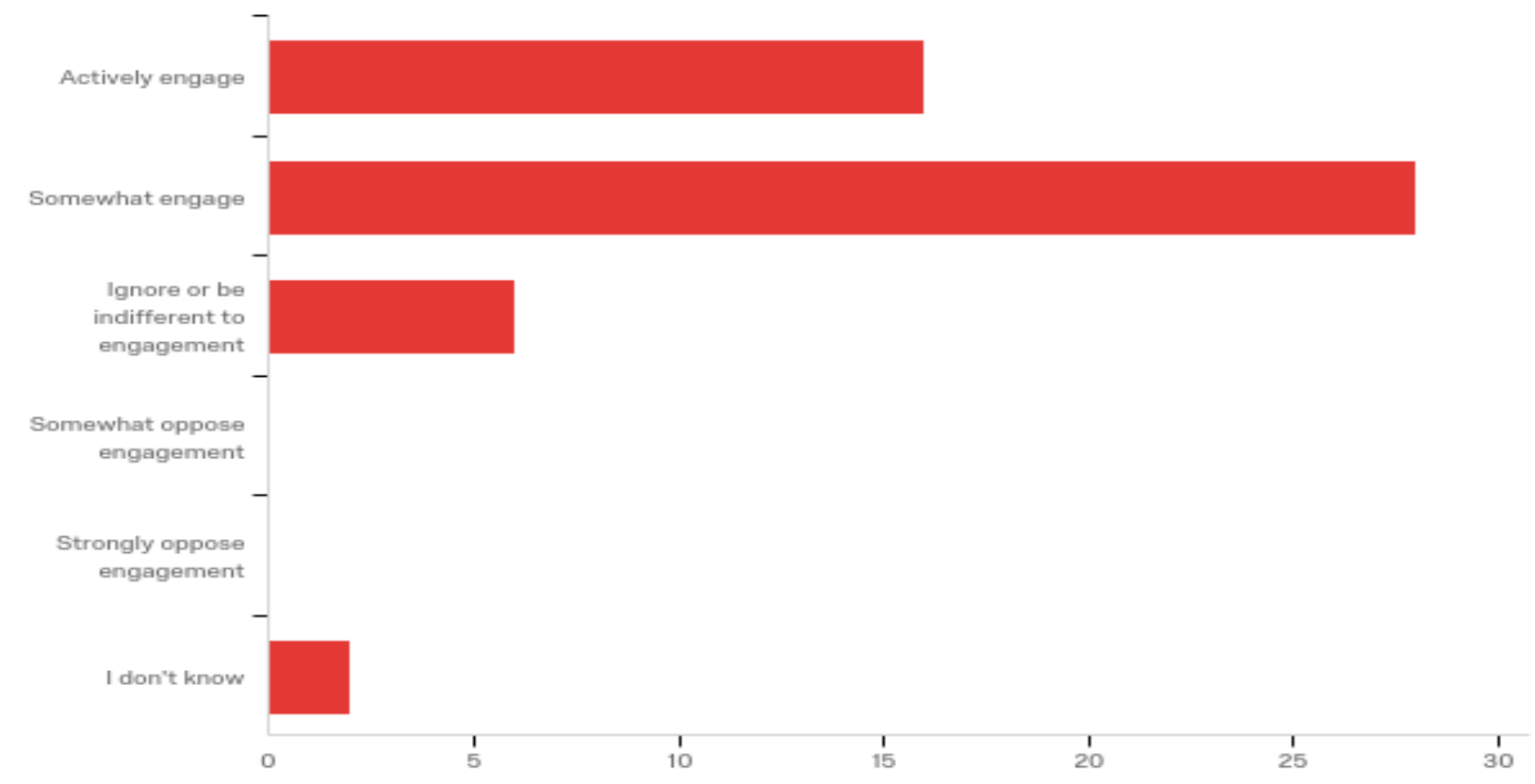

Q4 -What aspects of Public Impact-Focused Research are most likely to be accepted by researchers at your university? TEXT RESPONSES

Research that is based upon inspiring research questions that has the potential for positive change in the community 
If the public value was aligned well with academic valued aspects of research (which were aligned with metrics, incentives, and P\&T criteria [to be really specific]), this would make PIR more likely to be accepted by researchers AND administrators.

both opportunity to make an impact and to receive significant extramural support

Those that fall into the wheelhouse of ongoing activities and efforts.

The value of a publicly-funded university to address issues and concerns of their local and regional communities It varies by discipline. In some disciplines it is more about translational research. In other disciplines (Arts, Humanities, Design) it's more about social justice and systemic change research. In other disciplines (Management, Business, Engineering) it's more about research with business and industry. Some prefer placebased work (working within a geographic area, locally or nationally). Others are more issue-focused (health, poverty, the environment, achievement gap). Others are more partner oriented (non-profit, governmental, businesses, educational institutions, etc.). So it varies and depends on the particular discipline and interest of the faculty. It's definitely not a one-size or one-method fits all kind of thing.

social benefits; community engagement; indigenous engagement.

acknowledgement of their work in broader areas than their immediate field

Opportunities for collaboration for the social good

Impact on underserved communities, in education and healthcare

collaboration with community partners across the spectrum of community engaged research

Depends on the researchers - those that are already community-based researchers will not accept if they feel the "university" is stepping into their territory. For those, they must be at the table from the start. Researcher's who do not do community-focused research need to be educated on how to communicate the public impact of their work; for some of them, they then see the value (most just ignore)

Benefits to the community

I think a lot of researchers do this already. I view the campaign as an effort to increase people's degree and type of engagement and to raise the profile of those doing it. I view the ideal as partnering with the community to identify and work together to solve community-relevant issues. If there were support in terms of introductions, facilitation of administrative hurdles, funding, etc. all of these factors might encourage a faculty to venture into this area or increase their degree of engagement in this area.

Research that attracts external sponsors (government, industry, or philanthropic) that will provide access to funding for postdocs, graduate students, and cutting-edge equipment.

Depending on the discipline/field, the spectrum would be accepted by our researchers.

projects and programs that have potential to result in publishable material

We already do a tremendous amount of climate change research. Promoting this definition will not likely change the degree of effort invested.

inter-and multidisciplinary partners and community engagement

Projects where students are engaged and able to have impact.

interdisciplinary and trans-disciplinary projects that fit with their research focus areas

Those that are recognized in their performance reviews.

social good 
a) Relation to the land-grant mission and serving the public b) Leading-edge research c) Partnering with external stakeholders

work that leads to their research having an impact on their target, partnerships outside the university

if it was in the P\&T document as expected part of research

Interdisciplinary

Relation to the land-grant mission; must be leading-edge research that generates new knowledge; and partnering with institutions other than research universities.

Collaboration across disciplines to solve complex problems for our society. Opportunities to build partnerships for future opportunities. Create leaders who are focused on service and making a difference.

I am still fuzzy on the meaning, but it would be to contribute to the greater good through research that offers potential to solve societal problems.

the translation of cutting-edge research ideas into publicly-impactful practice

Opportunity to contribute and advance knowledge that is as important and appreciated at the discipline level as it is to the community at large.

People like being part of an interdisciplinary team, being engaged with external partners (enriches their view), they like being able contribute to something big and to make something happen.

economic development aspects; reporting out how "great" we are

We are a land-grant university with a very strong culture of benefitting the public. A good deal of our research is public impact-focused.

uncertain, work that benefits the public good

the public impact aspect

Most would argue they are already doing.

Those that are have a connection to Cooperative Extension (continuum between discovery and implementation with impact)

I'm not clear what this question is asking (i.e., "aspects"); it depends on the definition, which could range from science communication to effective interventions to policy change. Many of our researchers would support the importance of public impact (with variations by discipline).

Support for developing partnerships with external "receptors"

Value of applied research

Programmatic research that addresses pressing, critically important public/societal/environmental concerns, and that also has potential for new or continued funding support.

The great majority of researchers believe that their research will positively impact society though the timeline can differ greatly from discovery research to applied research. No faculty will be on-board if they feel they are being told what questions they should pursue in their research.

The sense of service and ensuring that we are benefiting society.

impact on society

All aspects

Public good aspect. But they will try and fit their research in context to satisfy the definition and continue what they do unless new funding is involved. 


\section{Q5 What aspects of Public Impact-Focused Research are most likely to be opposed by researchers at your university? TEXT RESPONSES}

risk that it may not be recognized, for purposes of promotion and tenure, for example, as more traditional modes of research; perceived obstacles in identifying relevant partners;

Aspects that are "determined" by others to be less rigorous, more common sense or antithetical to what is determined to be representative of "quality" research. Determination and quality can be domain/discipline specific which makes discussing PIR centrally more of a challenge than within and across domains.

perception of direction to their choices of activities

More senior faculty who believe that the only academic research mission is basic fundamental science will naturally oppose such efforts.

Faculty could become opposed if there is a sense that public-impact focused research is being overly emphasized compared to more fundamental and curiosity-driven research

Those that are not reciprocal in nature with community partners (i.e, outreach work or public service work that is only about benefitting the researcher and not the community partner(s))

lack of recognition for purposes of promotion \& tenure; availability of relevant funding

Any reporting functions that might be associated with it

Misperception that it will de-value individual research

Projects that has negative impact on the environment, population health, and gun violence

research that utilizes public partners as participants but without any involvement of partners in research development and implementation

See previous comments

Benefits to industry or for-profit sectors.

I don't know that anything will be opposed unless there is a perception that funding or priorities are regular communication with external stakeholders at the expense of time that could be devoted to project implementation

no outlet for publication as a result of the research

not sure

not sure-i'm always surprised at the issues that set faculty off

Projects/Topics that generate harsh reactions from politicians

project where they have no possibility of resources or future relevance to their expertise and area(s) of research focus

Don't know.

none

Any project with insufficient research and scholarly activity; some resistance to industrial engagement.

not valuing "pure" basic research, being seen as applied

they will see it as another unfunded mandate or will feel left out if they do basic research

Must include an external partner 
Anything with too little research/scholarly activity. Some opposition to research involving industry as well.

Some may find it difficult to navigate approval processes within state and federal governments. Should provide assistance to help streamline that process.

There wouldn't be any substantive opposition as we are a land grant institution, and sharing knowledge with the public is core to our missions.

Mandated engagement

Mandated or imposed engagement that is not recognized or valued.

all research has to have an applied aspect, though this would simply require improved definition

In the true spirit of academic freedom, I would expect our researchers to oppose initiatives that are top-down and mandatory.

misunderstanding PIF as an implicit institutional instruction to change the direction of their research

More work to do without additional support if not working in cooperation with Extension; more likely that researchers are unable to make time for community connections really needed for impact

Still not clear, but reward structures are always an issue.

Anything that comes across as though it's the sole focus of the university.

Lack of appropriate funding for the research

Research program(s) that are mandated, without taking care and time to build consensus and interest.

If faculty believe that their research agenda is being defined by others, there will be a strongly negative response.

Are we ignoring basic research after all the typical cell phone is great but the compilation of very basic research that was assembled to make a cell phone possible was also critical work.

that it has to involve external participation

None, unless it is actually work-for-hire, rather than actual research.

Public good may be seen as short term application and dissemination projects instead of basic research.

\section{Q6 - Thinking about current research at your university, do you feel the general trend is:}

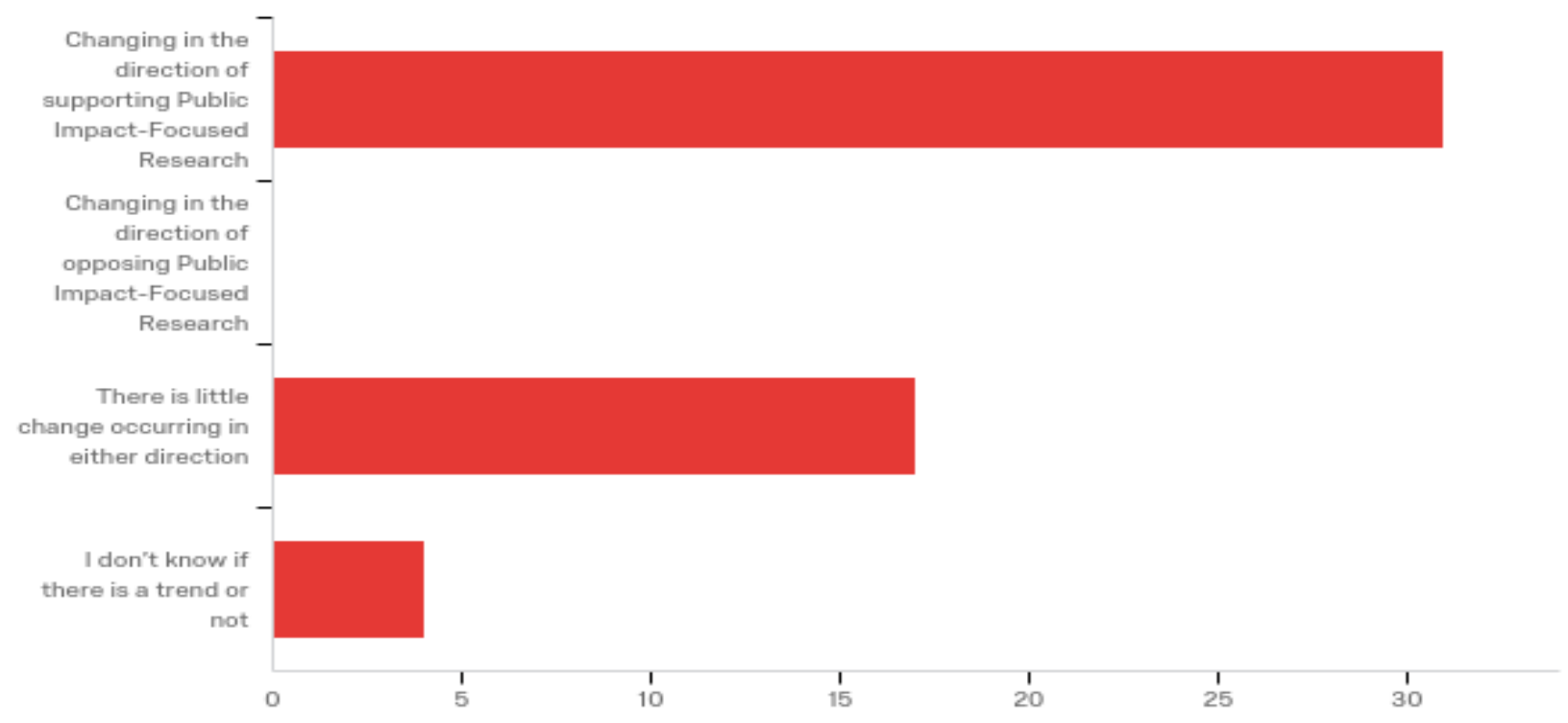


Q7 - Roughly what percentage of the research activity at your university do you believe is currently public-impact focused, as we have defined it (research conducted for the explicit purpose of benefiting the public)?

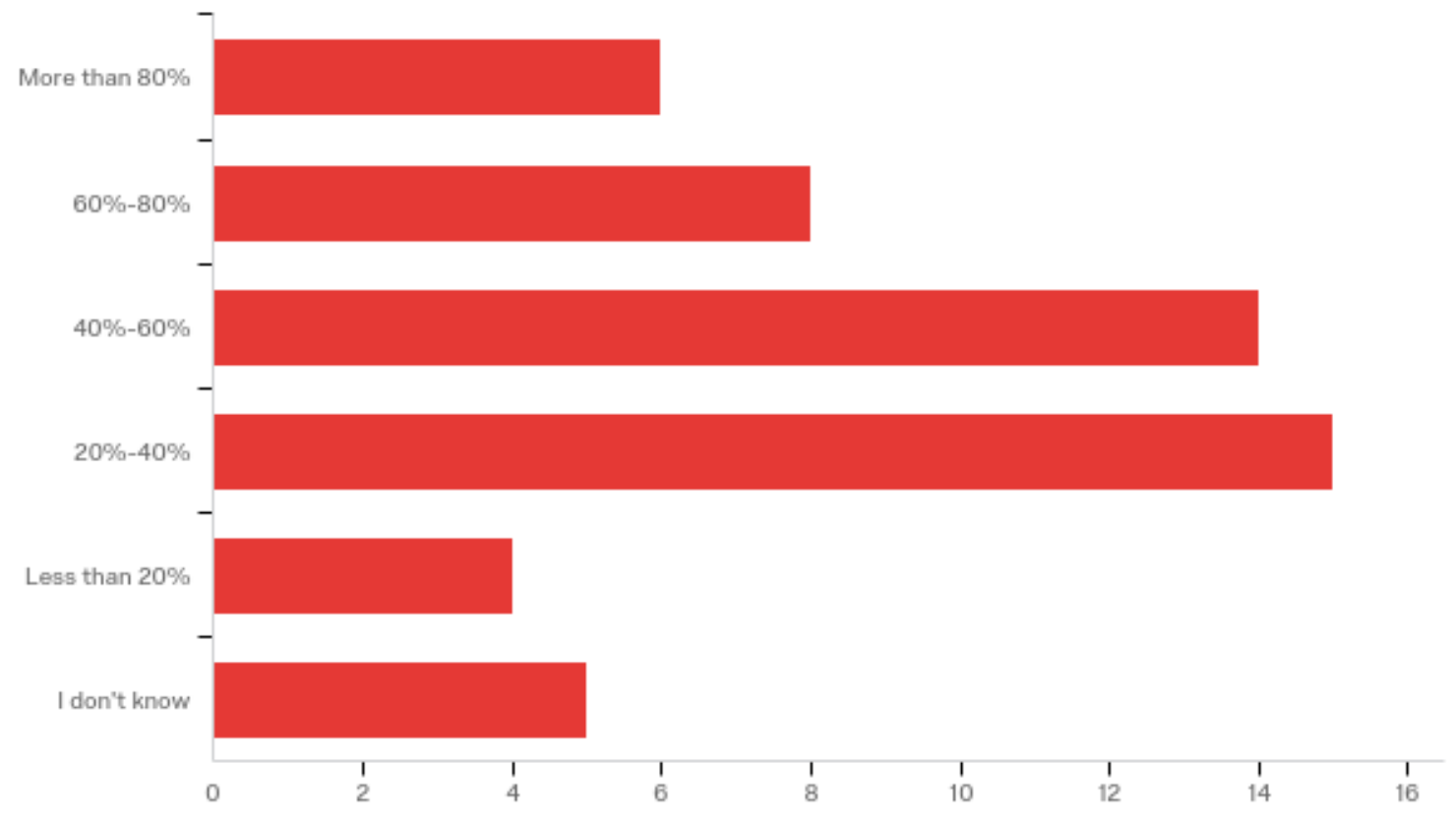

Q8 - What research disciplines at your university are most involved in Public Impact-Focused Research? (select all that apply)

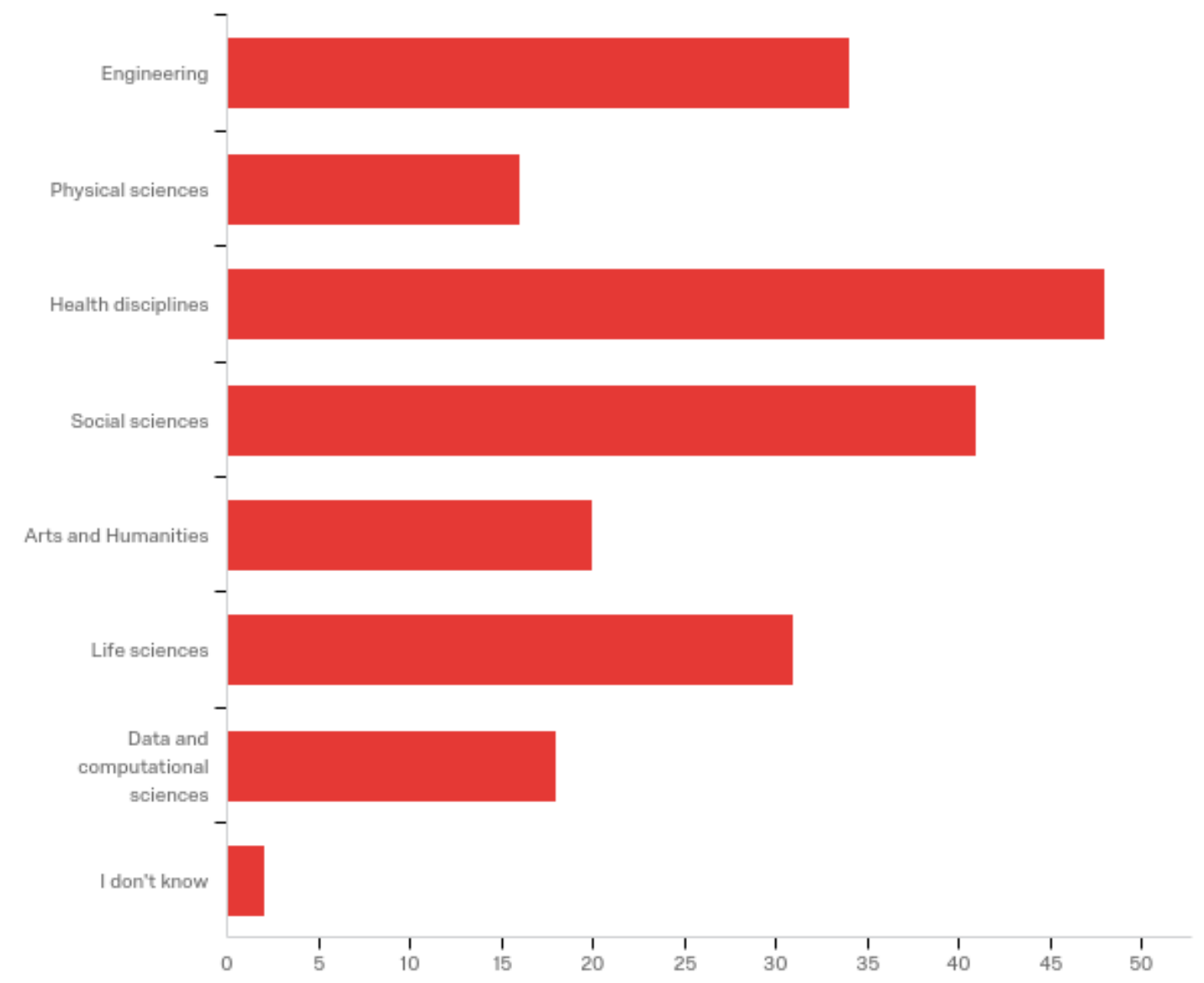




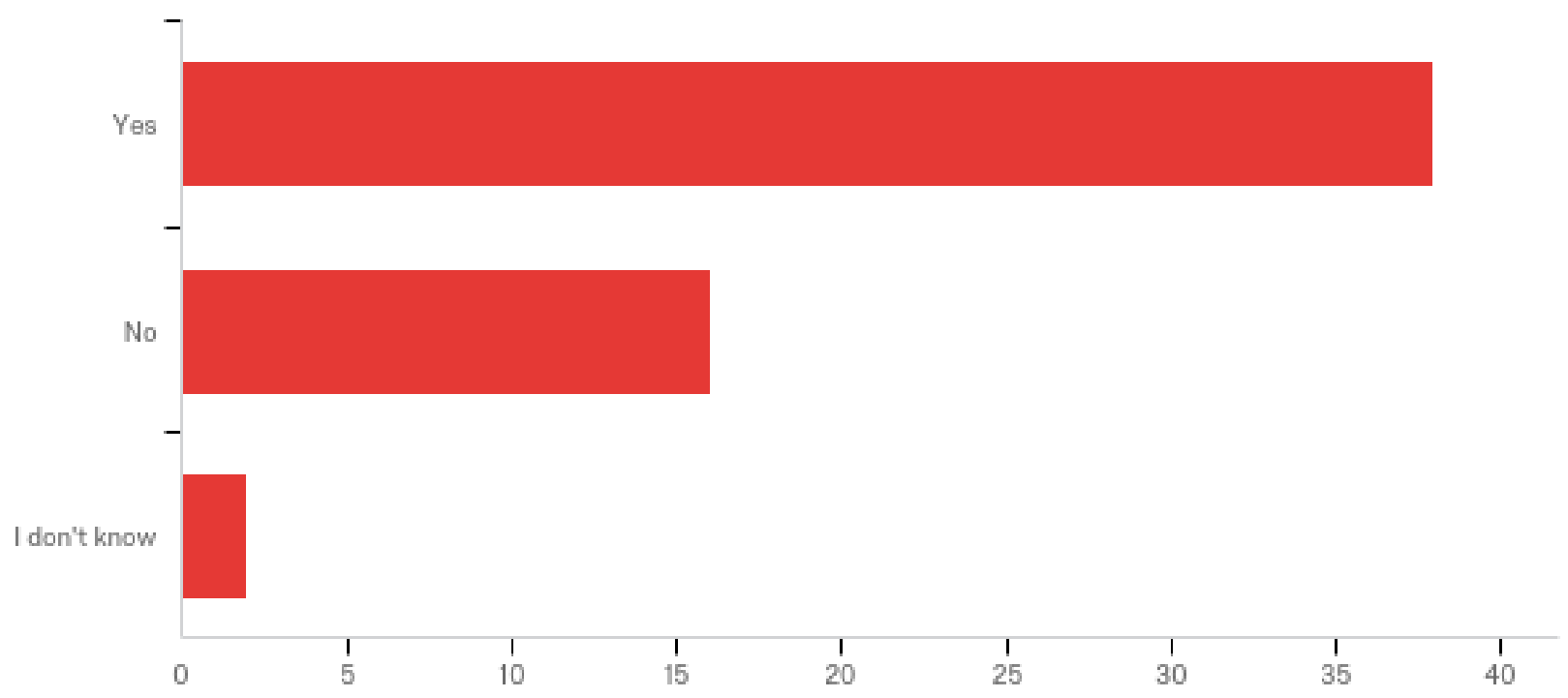

\section{Q10 - Please provide the name of this initiative(s) and web link, if available. TEXT RESPONSES}

We are holding a conference on this topic and we have some task forces directed toward specific challenges-Water, Opioid, Mass Violence www.utoledo.edu/research/symposium;

http://www.utoledo.edu/commissions/water-task-force/

Strategic Plan: Our Commitment to Impact (http://strategicplan.psu.edu/)

The effort at UTA comes from the strategic plan, which emphasizes enabling the sustainable megacity with a focus on addressing regional issues that can also have a global impact.

We have numerous initiatives, some are campus-wide while others are focused specifically within collages or discipline areas. Here are just a few: https://engagement.umn.edu/engagedscholar

;https://engagement.umn.edu/about-engagement/review-committee-community-engaged-scholarship; https://engagement.umn.edu/engaged-scholar-directory; https://www.ctsi.umn.edu/consultations-andservices/community-engaged-research; https://engagement.umn.edu/our-impact/engaged-department-grantprogram; https://research.umn.edu/about-us/initiatives/convergence-colloquia;

https://research.umn.edu/about-us/initiatives/convergence-colloquia/citizen-science UBC Sustainability Initiative (https://sustain.ubc.ca/); Community Engagement (http://communityengagement.ubc.ca/)

grandchallenges.unm.edu

http://www.uh.edu/research/about/thrusts/ ... Institutional Thrusts

A relative new initiative is the Center for Community Health Equity Research; (http://www.umass.edu/research/engagement/centers-and-institutes); other initiatives are for example, the Public Engagement Project: https://www.umass.edu/pep/publications/public-engagement

Urban Impact (https://www.uc.edu/strategicdirection.html\#urban-impact)

Depression Grand Challenge \& Sustainable LA Grand Challenges https://grandchallenges.ucla.edu/ Institute of Genomic Biology, The Beckman Institute, NCSA, Institute for Sustainability, Energy, and the Environment, Prairie Research Institute, Cancer Center at Illinois, Center for Social and Behavioral Sciences, Illinois Program for Research in the Humanities (IPRH), 
one of our guiding priorities to meet our land grant mission

"One Health" is one example where the primary focus is the public good:

https://www.uaf.edu/onehealth/index.php

https://www.uab.edu/dei/cace

We have multiple such university-wide initiatives. Two major ones are urban@uw

(https://depts.washington.edu/urbanuw/), Population Health (https://www.washington.edu/populationhealth/),

Data Science for Social Good (https://escience.washington.edu/get-involved/incubator-programs/data-science-

for-social-good/).

WSU Grand Challenges and Strategic Research Investments; see https://research.wsu.edu/research-

initiatives/grand-challenges/ and https://research.wsu.edu/research-initiatives/strategic-reallocation-researchprojects/

http://wmuace.com/

Grand Challenges and Strategic Research Investments

https://www.research.msstate.edu/ci/

Presidential Interdisciplinary Research Initiative, https://www.vpresearch.iastate.edu/research-iowa-state/piri/

Public Impact-Focused Research does not reside in a single initiative on the UNCG campus.

At this institution PIR is not housed in one single initiative. Initiatives usually do not outlive a single initiating individual. At UNCG, we are the Office of Research and Engagement. Engagement is pervasive. ICEE

Community Engagement, no link yet, under development

Our university-wide initiatives stem from our land-grant mission. It is woven through many--although perhaps not all--of our college and departmental websites either explicitly or implicitly.

Discovery Themes: https://discovery.osu.edu/ and Time and Change strategic plan:

https://president.osu.edu/strategicplan/

Cooperative Extension - it is in all 50 states!

Knowledge exchange unit with innovation portfolio www.innovation.ubc.ca

We are launching large research initiatives in climate change, coastal resiliency, mitigation of ocean plastics pollution, and access to fresh water and food sustainability.

Brain Health Research Institute, Advanced Materials and Liquid Crystal Institute, Healthy Communities Research Initiative, Environmental Science and Design Research Initiative, Global Understanding Research Initiative, Design Innovation Research Initiative

"Let knowledge Serve"

\section{Q11 - Indicate approximately how much funding (\$/year) your university has provided specifically to support this initiative(s). (Please enter a number or skip if you don't know.)}

Responses to this question were not included because they were skewed by values that were clearly not correct.

\section{Q12 - Indicate approximately how much external funding specifically supports this initiative(s). (Please enter a number or skip if you don't know.)}

Responses to this question were not included because they were skewed by values that were clearly not correct. 
Q13 - About what percent of your faculty are involved in these initiatives?

\begin{tabular}{|l|r|r|r|r|r|r|r|}
\hline$\#$ & Field & Minimum & Maximum & Mean & Std Deviation & Variance & Count \\
\hline 1 & \% of faculty & 2.00 & 80.00 & 31.43 & 24.14 & 582.89 & 28 \\
\hline
\end{tabular}

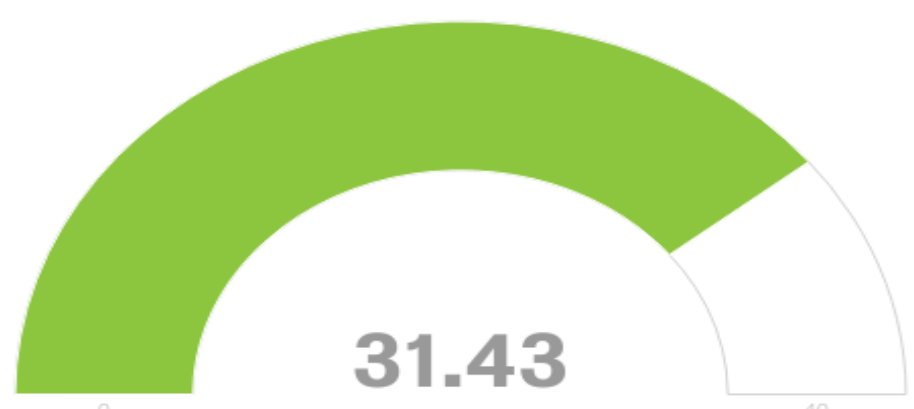

Q14 - About how many external (non-university) partners are engaged in these initiatives?

\begin{tabular}{|r|r|r|r|r|r|r|r|}
\hline$\#$ & Field & Minimum & Maximum & Mean & $\begin{array}{r}\text { Std } \\
\text { Deviation }\end{array}$ & Variance & Count \\
\hline 1 & Funders & 1.00 & 20.00 & 10.83 & 7.09 & 50.23 & 23 \\
\hline 2 & Non-governmental organizations & 1.00 & 20.00 & 8.13 & 6.24 & 38.90 & 23 \\
\hline 3 & State agencies & 0.00 & 20.00 & 7.09 & 6.32 & 39.99 & 23 \\
\hline 4 & Community partners (health, planning, & 1.00 & 20.00 & 8.89 & 7.16 & 51.32 & 18 \\
\hline
\end{tabular}

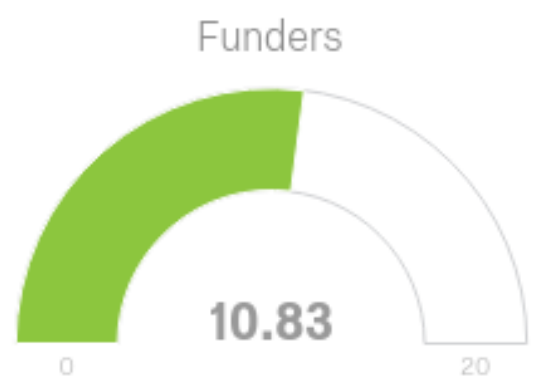

\section{State agencies}

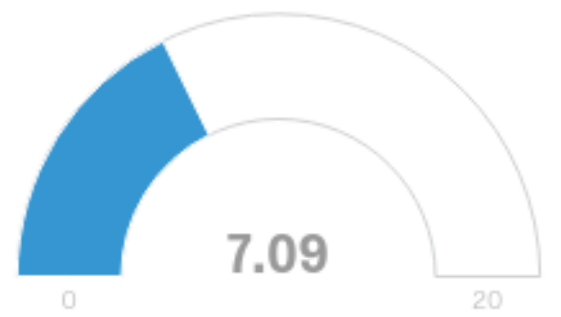

Non-governmental organizations

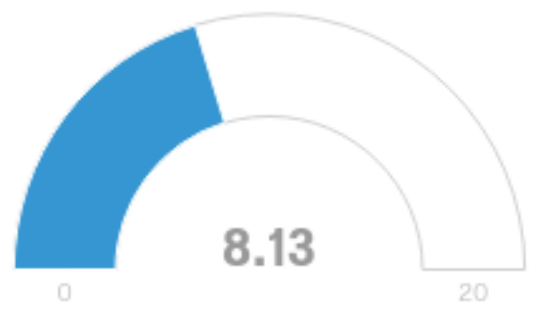

Community partners (health, planning, other)

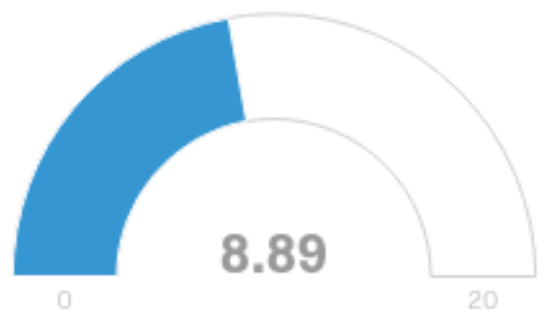


Q15 - Thinking about any initiatives now in place on your campus, do you have strategic communications that specifically support these Public Impact-Focused Research projects?

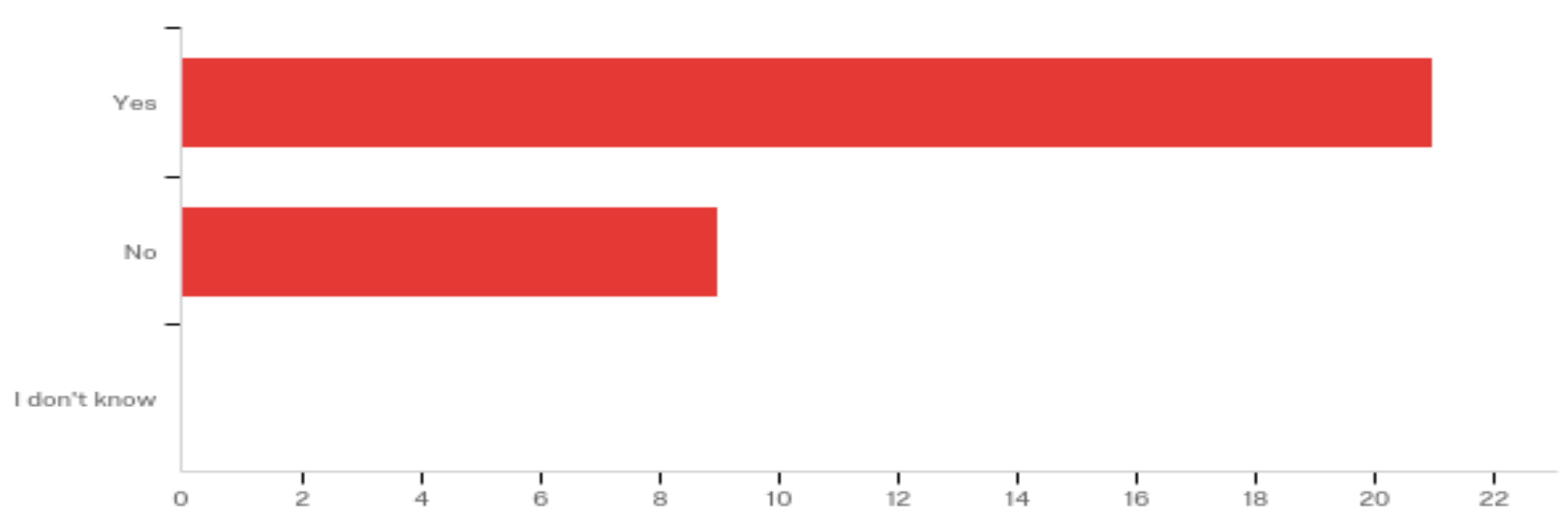

Q16 - Do you think these strategic communications have been effective in achieving the stated purpose?

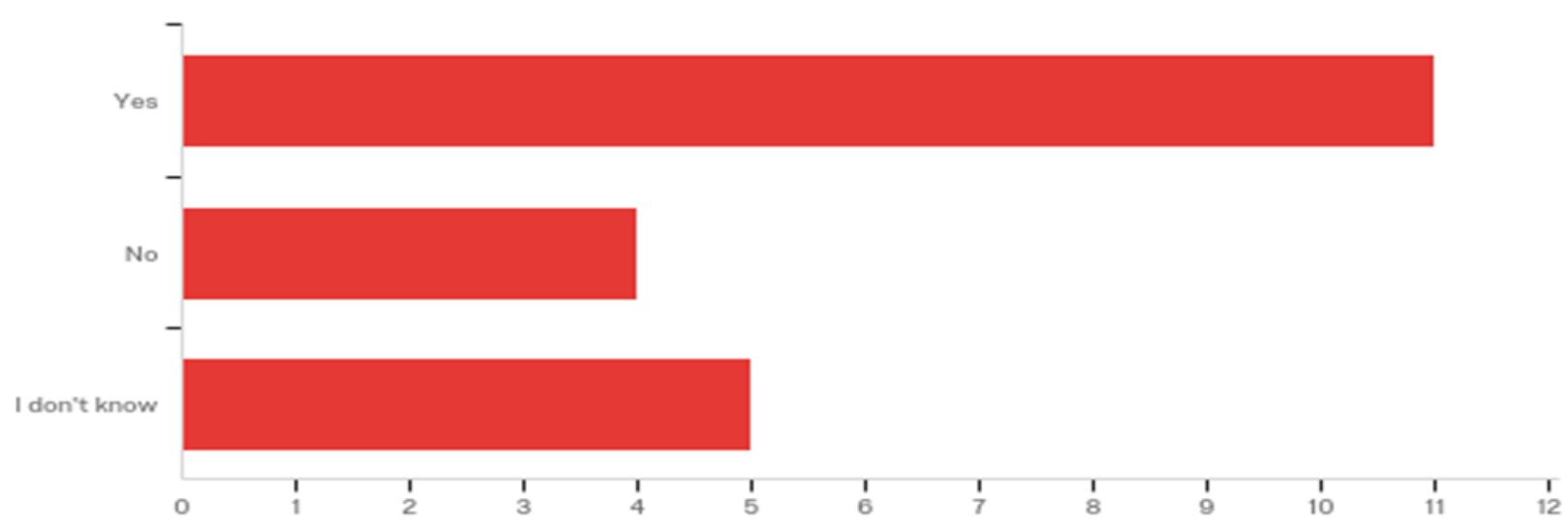

Q17 - What are the primary reasons that strategic communications support your Public Impact-Focused Research initiatives?- Answer

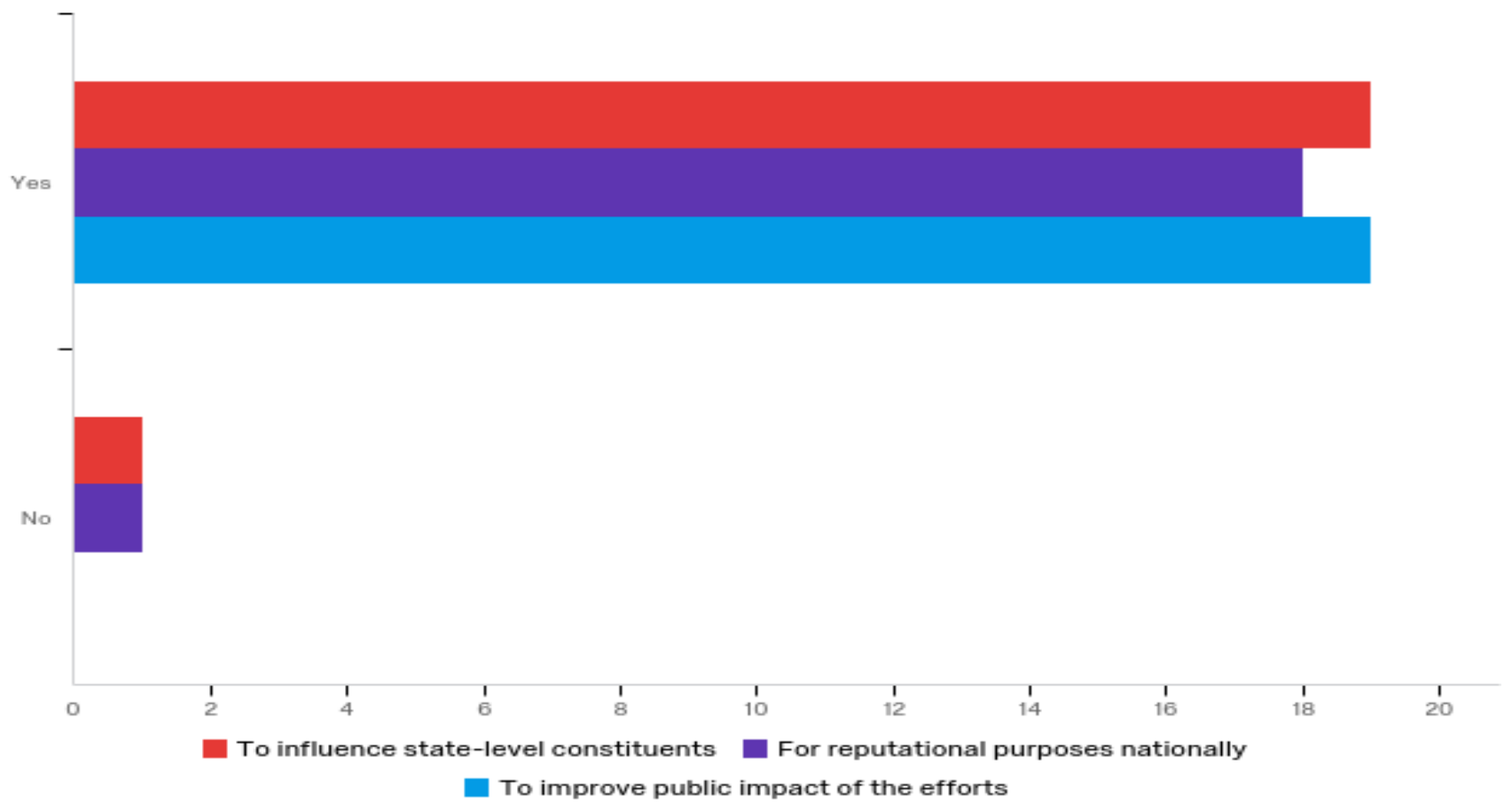


Q18 - What, if any, specific nomenclature do you use to talk about the Public Impact-Focused Research initiative(s) at your university?

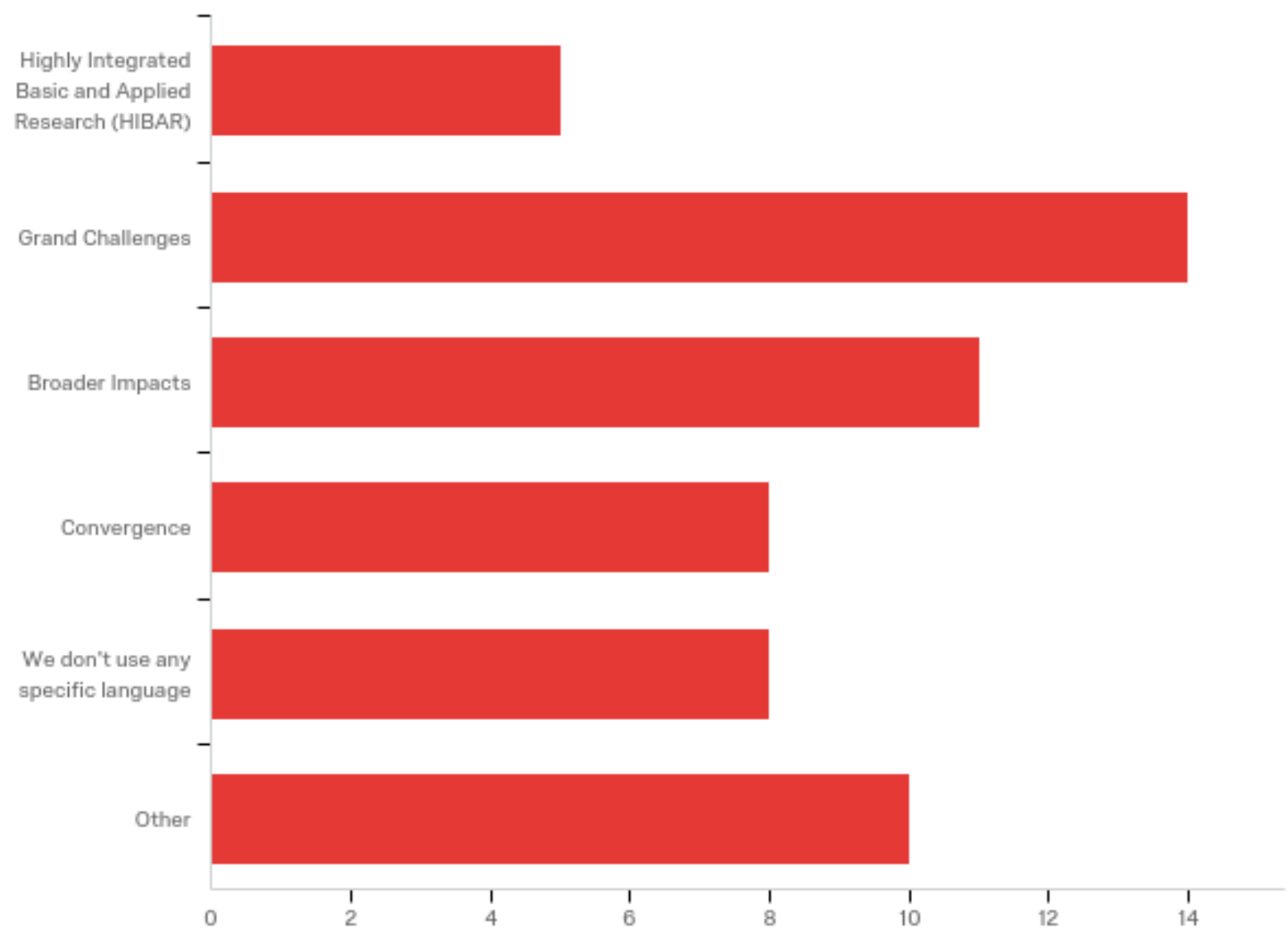

\section{Q18 Other - TEXT RESPONSES}

Impact, Implementation; Translation

Publicly-engaged research, community-based participatory research; reciprocal research engagement Societal Challenges

Community Engaged Research

Interdisciplinary Research

Synergistic Opportunities

community engaged, community engagement, R \& D partner, backbone organization,

Discovery Themes

Public Value

Knowledge exchange 
Q19 - We are interested in the challenges you have experienced in getting Public Impact-Focused Research done at your university. Please indicate whether each of these issues is not a problem, a moderate problem, or a large problem

\begin{tabular}{|c|c|c|c|c|c|c|c|c|c|c|}
\hline \# & Question & $\begin{array}{l}\text { Not } \\
\text { sure }\end{array}$ & & $\begin{array}{r}\text { Not a } \\
\text { problem }\end{array}$ & & $\begin{array}{l}\text { Moderate } \\
\text { problem }\end{array}$ & & $\begin{array}{r}\text { Large } \\
\text { problem }\end{array}$ & & Total \\
\hline 1 & $\begin{array}{r}\text { Getting leadership (Deans and } \\
\text { above) to recognize and value } \\
\text { Public Impact-Focused Research as } \\
\text { a campus priority. }\end{array}$ & $2.08 \%$ & 1 & $52.08 \%$ & 25 & $41.67 \%$ & 20 & $4.17 \%$ & 2 & 48 \\
\hline 2 & $\begin{array}{l}\text { Researchers' ability to work } \\
\text { together across disciplines }\end{array}$ & $0.00 \%$ & 0 & $44.90 \%$ & 22 & $48.98 \%$ & 24 & $6.12 \%$ & 3 & 49 \\
\hline 3 & $\begin{array}{r}\text { Getting clarity on researchers } \\
\text { having a shared purpose }\end{array}$ & $4.17 \%$ & 2 & $35.42 \%$ & 17 & $50.00 \%$ & 24 & $10.42 \%$ & 5 & 48 \\
\hline 4 & $\begin{array}{l}\text { Uncertainty about the value of } \\
\text { Public Impact-Focused Research in } \\
\text { promotion and tenure }\end{array}$ & $8.33 \%$ & 4 & $16.67 \%$ & 8 & $52.08 \%$ & 25 & $22.92 \%$ & 11 & 48 \\
\hline 5 & $\begin{array}{l}\text { Finding internal funding or } \\
\text { resources to support Public } \\
\text { Impact-Focused Research }\end{array}$ & $0.00 \%$ & 0 & $10.42 \%$ & 5 & $37.50 \%$ & 18 & $52.08 \%$ & 25 & 48 \\
\hline 6 & $\begin{array}{l}\text { Finding external funding to support } \\
\text { Public Impact-Focused Research. }\end{array}$ & $2.08 \%$ & 1 & $18.75 \%$ & 9 & $50.00 \%$ & 24 & $29.17 \%$ & 14 & 48 \\
\hline 7 & $\begin{array}{l}\text { Difficulty in finding non-university } \\
\text { partners with whom to work }\end{array}$ & $2.08 \%$ & 1 & $56.25 \%$ & 27 & $39.58 \%$ & 19 & $2.08 \%$ & 1 & 48 \\
\hline 8 & $\begin{array}{r}\text { Difficulty in working with external } \\
\text { partners (different agendas, foci, } \\
\text { expectations, or other) }\end{array}$ & $4.26 \%$ & 2 & $61.70 \%$ & 29 & $27.66 \%$ & 13 & $6.38 \%$ & 3 & 47 \\
\hline 9 & $\begin{array}{r}\text { Lack of institutional support and } \\
\text { resources needed. }\end{array}$ & $0.00 \%$ & 0 & $38.30 \%$ & 18 & $38.30 \%$ & 18 & $23.40 \%$ & 11 & 47 \\
\hline 10 & $\begin{array}{l}\text { Uncertainty about how to measure } \\
\text { the impact or success of Public } \\
\text { Impact-Focused Research on your } \\
\text { campus. }\end{array}$ & $2.13 \%$ & 1 & $31.91 \%$ & 15 & $44.68 \%$ & 21 & $21.28 \%$ & 10 & 47 \\
\hline
\end{tabular}


Q20 - How does your university support faculty/staff/students wishing to conduct Public Impact-Focused Research? (Check all that apply.)

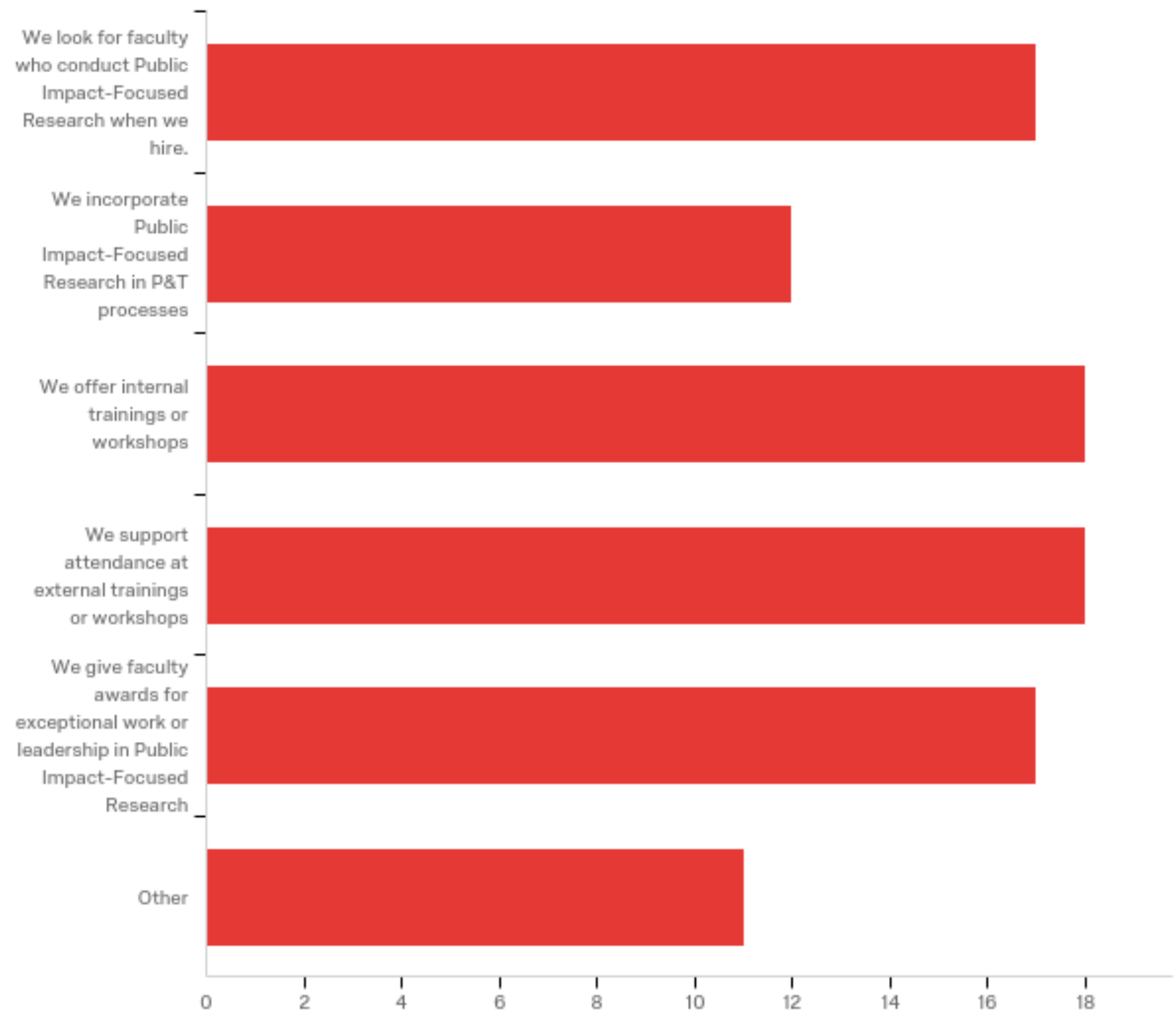

\section{Other - TEXT RESPONSES}

We prepare future faculty for public engagement research by incorporating community-engaged research into our graduate programs

We look for examples of public Impact-Focused Research within the existing portfolio

Provide seed funding

Internal competitive funding focused on societal challenges

WE allow faculty to pursue this research (often are low F\&A or IDC grants that do not cover their management costs).

We offer seed funding when we want to encourage something

None

we facilitate research collaborations with the city 
We work to build infrastructure (e.g., networks, resources) to facilitate this for faculty, staff, and students; we catalog and share PIR work from around the institution; We convene groups to support connections within geographical or disciplinary areas; None of this is framed as public impact-focused research - it's framed as engaged scholarship.

none of the above

\section{Q21 - Is Public Impact-Focused Research, in any or all of its forms, a strategic thrust of your university that is recognized by higher administration officials (Deans and above)?}

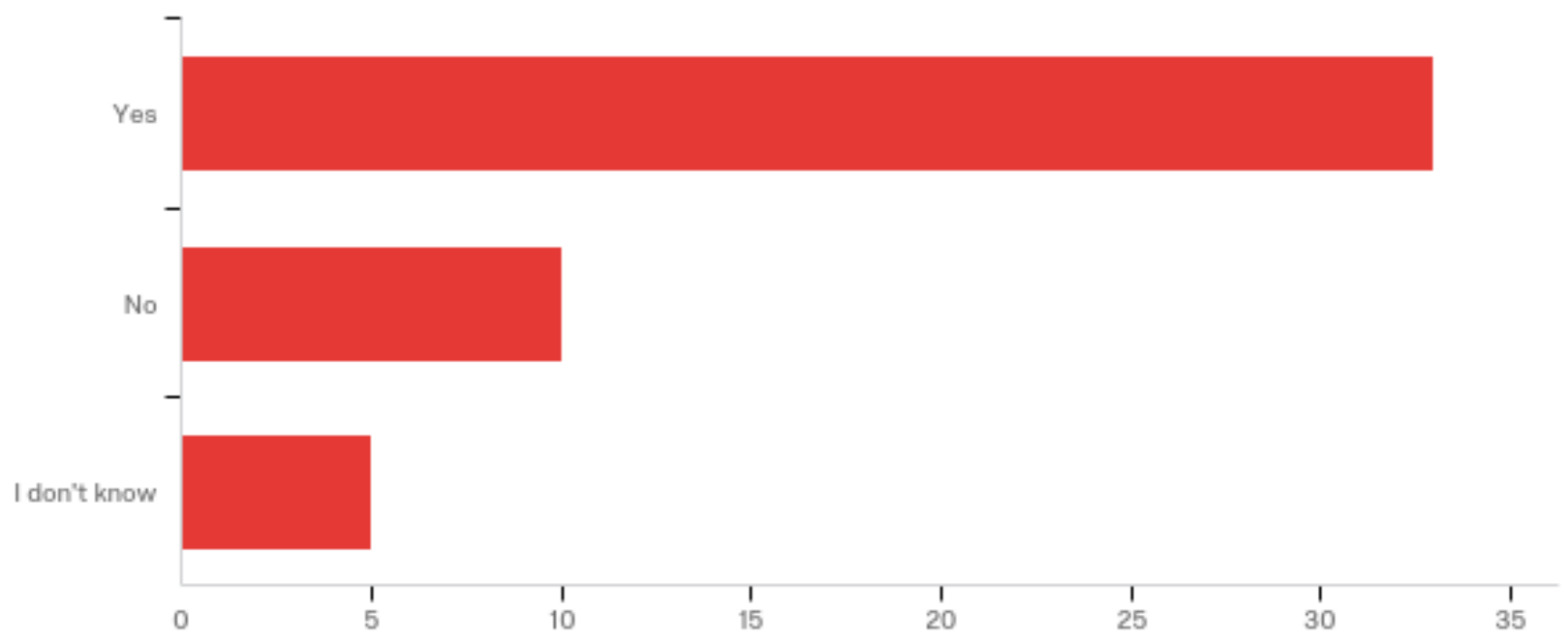

Q22 - Does your university have policies, guidelines, or practices related to documenting and assessing the contribution, quality, or impact of scholarly products generated from Public Impact-Focused Research? If so, please describe these below and/or provide a web link if available.

All of our departments have incorporated language on public engagement in their faculty promotion, review, and tenure policies Here is the link to each department's guidelines: https://faculty.umn.edu/promotiontenure/approved-712-statements

Departmental and College Bylaws for tenure and promotion

https://provost.illinois.edu/policies/provosts-communications/communication-9-promotion-and-tenure/

I browsed a few of the P\&T documents in Arts and Sciences and most did not include any credit for PIF research. One dept that does do externally focused work did acknowledge it, but interestingly, made it second tier work (https://faculty.wvu.edu/files/d/5338ca77-efcc-42f7-a94e-9b27214f8814/puba-final-6-10-10.pdf). The school of medicine has an innovation and impact statement in their guidelines, which is the only document to do so to my knowledge: https://faculty.wvu.edu/files/d/cd67b983-c650-480b-8ce2-8a393ef98b57/som-p-t-guidelines-

revised-2017-docx.pdf (p. 7)

Not much- you can check off whether or not a grant proposal supports the Grand Challenges.

Yes, broad range of policies establishing and operating research institutes and centers. Also policies regarding research conduct and ethics.

We have a professional practice component to P\&T that includes more public-facing activities. That doesn't mean it is always valued in local P\&T discussions.

https://communityengagement.uncg.edu/wp-

content/uploads/2014/08/UNCG_Community_Engagement_TermsDefinitions_030111.pdf

https://www.fau.edu/community/ 
Part of the evaluation and promotion process for Cooperative Extension Specialists and Advisors

https://engage.msu.edu/upload/documents-reports/pod_2009ed.pdf

\section{Q23 - Is there anything else you feel we should know about the characteristics, challenges, or importance of Public Impact-Focused Research at your university? TEXT RESPONSES}

Is there anything else you feel we should know about the characteristics, challenges, or importance of Public Impact-Focused Research at your university?

Educational/pedagogical and agricultural research appeared to be missing from choices in Q8. That question could have been made more complete with additional choices or the ability to complete an "Other" choice.

It should comprise a significant portion of what we and all public institutions do.

Public Impact-Focused Research is not a term our university uses because it connotes at 20th Century approach to traditional outreach. We have adopted the term "public engagement" which has a formal definition (approved in 2006) that focuses on reciprocal engagement and partnerships with communities. Public Engagement at our university is about working WITH community partners and honoring the knowledge and expertise that reside outside of the academy to produce higher impact societal outcomes of our research. Our promotion and tenure guidelines were revised 2007 whereby every department was required to articulate how it would incorporate public engagement in the promotion and review of faculty. The University offers a President Community Engaged Scholar award whereby each college can nominate one individual as the collegiate community-engaged scholar whose research has demonstrated impact on the community. Each of the collegiate recipients become eligible for the Presidential award. We have other awards, faculty development programs, grant programs, interdisciplinary, issue area hubs focused on different community issues, grand challenges research grants, and many other initiatives that have been built and integrated into the University's culture over the last 20 years. Much of the work is overseen by the University's Public Engagement Council, which has addressed close to 40 policies issues to remove barriers to conducting high impact publicly-engaged research. See https://engagement.umn.edu/aboutengagement/public-engagement-council

This concept isn't widely understood across my institution among administration, faculty, or staff.

It has generated enthusiasm among a large number of faculty

coordination of variety of projects in similar communities is difficult; it would be good to get information about how other universities do such coordination

Ours is nascent - part of our President's Strategic Directions that are just now rolling out...still early in the process so in the socialization phase, primarily

The major thing standing in the way are low IDC or F\&A to support these projects. That hampers the extent of our participation as we use grants that bring in our federally negotiated rates (F\&A or IDC) to subsidize the cost of low F\&A or IDC grant management.

On the "problems" question, I would say that some of my responses would have been better characterized as not a "problem" but a challenge/difficulty. A second point I would make that I'm sorry I didn't make earlier is that we should be finding out if school leaders are held accountable for campus priorities. If not, then they aren't really priorities. That's a problem or challenge. People may be supportive unless/until they need to use their resources to fund it.

We are a public university and there is a growing recognition at our university that taxpayers expectations for public impact of publicly funded research are strengthening.

The perception such initiatives must be huge, require enormous funds and are only possible at very large institution.

I was part of a team that looked at scholarly impact for research in management in business:

http://aom.org/About-AOM/StrategicPlan/Scholarly-Impact-Report.aspx 
Communicating the public impact of our PIR research is very important- we can never do that too much!

We embrace a diverse and multifaceted role as a comprehensive research university. These priorities also recognize a funding environment that will become increasingly challenging for the foreseeable future.

Some of the challenges noted earlier aren't because of PIR, but other factors in the university.

The working definition of Public Impact-Focused Research as presented reads as non-specific/diluted; all research benefits the public. Perhaps a working definition for PIR could include reference to research

initiated/implemented in response to priorities set by the public, projects that involve public partnerships. Public impact-focused research frames a project that advances public understanding of, and access to, information and includes the application and translation of the research to practice (see the National Implementation Research Network). This research is relevant to public priorities, responsive to public issues and is driven by public/community engagement. With respect to Q19. Without definitions of what constitutes a large or moderate problem it was difficult to assess each of the item. All of the items have slight, but different problems associated with the. From the perspective of this institution, public impact-focused research does not reside in a single initiative or in a single institution/entity.

Every LGU has a Cooperative Extension mission. I am unclear why APLU does not know this.

Our university focuses on "engaged scholarship." We have support for the engaged scholarship mission, and have been making strategic efforts to tie it to NSF broader impacts, public humanities, Cooperative Extension activities, economic development. It is one of the three part of our core mission. A university-wide strategy to build culture for and recognition of the benefits and challenges of this work at multiple levels would be a significant move forward.

Our public-impact research programs have taken on deeper meaning and increased importance, in partial response to current Federal political (executive branch) problems and failures.

There is a real danger that tightly defining Public Impact-Focused Research, will lead to a devaluation of basic discovery research which is the "pipeline" for applied research.

Our university has always conducted public-impact focused research (e.g., much more than fundamental research)so many of the questions above to do not apply. there does not seem to be a need for strategic initiatives or new policies or guidelines, as they are fully baked in already.

\section{Q24- Removed: this question was a call for volunteers and provided identifiable information.}

Q25 - This survey is being sent to university leaders in research and engagement. To help us better understand our responses, please indicate your role at your institution.

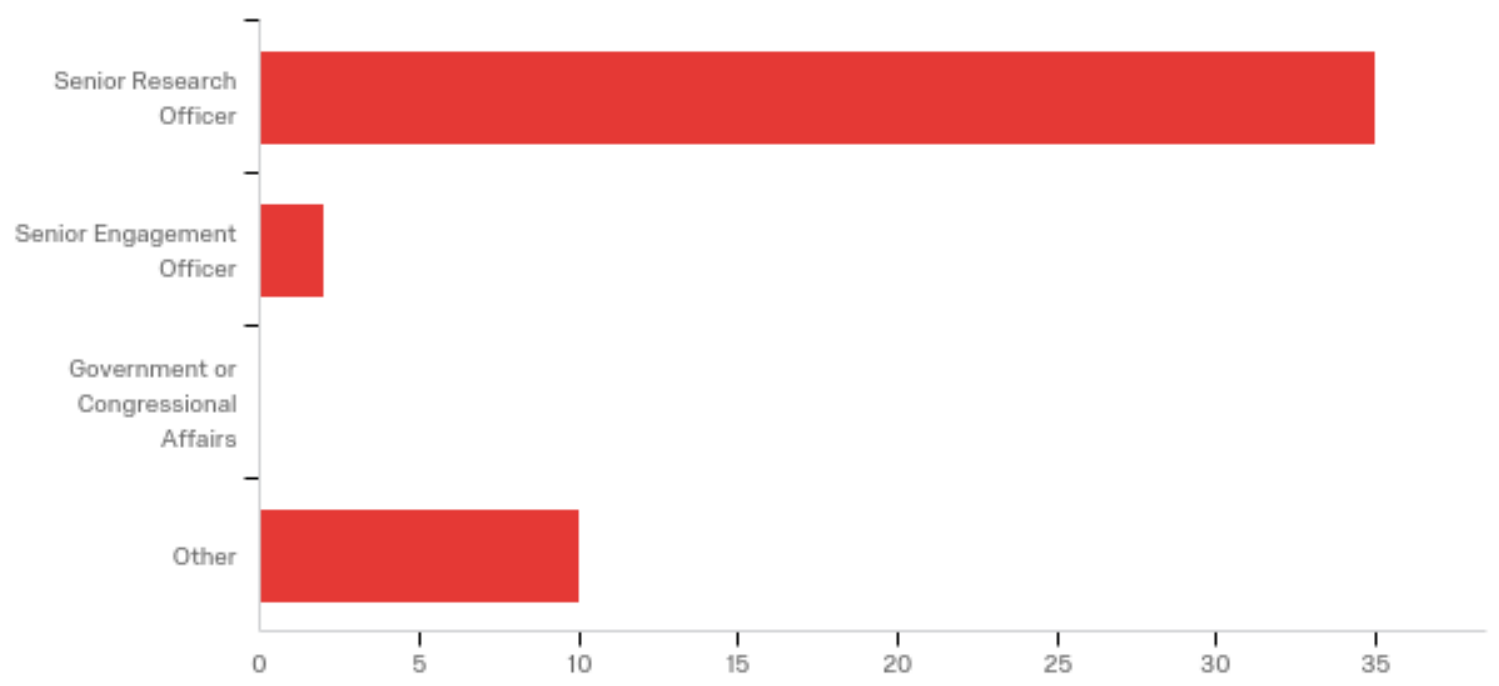

